
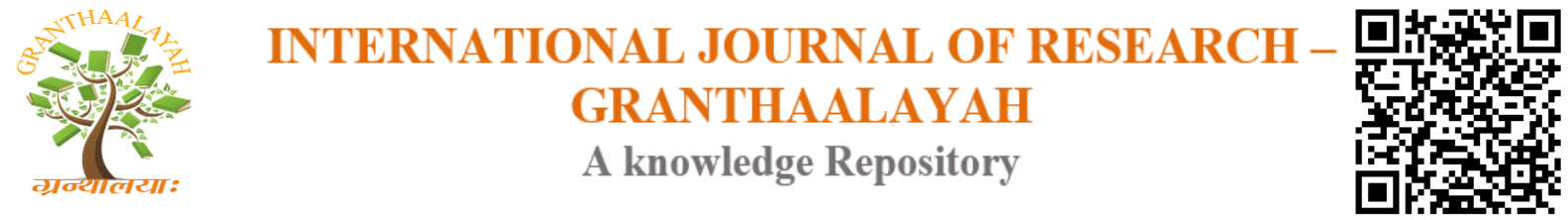

Science

\title{
RELATIONSHIP BETWEEN ATTACHMENT AND ADJUSTMENT WITH CHRONIC PAIN; WITH STUDY THE MODERATOR ROLE OF RESILIENCY
}

\author{
Sakineh Julaieha $^{* 1}$, Mahnaz Aliakbari Dehkordi ${ }^{2}$, Farhad Shagaghi ${ }^{3}$ \\ Afsaneh Lak ${ }^{4}$, Marzieh kakanejadi fard ${ }^{5}$ \\ ${ }^{*}$ PhD Candidate of Psychology, Department of Psychology, Payame Noor University, IRAN \\ ${ }^{2}$ Assistant Professor, Department of Psychology, Payame Noor University, IRAN \\ ${ }^{3}$ Master, Department of psychology, Payame Noor University, IRAN \\ ${ }^{4} \mathrm{PhD}$ Candidates of Elm O Farhang Univers, IRAN \\ ${ }^{5}$ MSc Clinical Psychology, Azad University of Ahvze \\ DOI: https://doi.org/10.29121/granthaalayah.v4.i8.2016.2563
}

\section{ABSTRACT}

The present study investigated the relationship between attachment style with adjustment and resiliency in chronic pain patients and probable mediating role of resiliency between attachment and adjustment.

Adult Attachment Inventory; Depression, Anxiety, Stress Scale (DASS_21) Resiliency Scale (CS_RISC) and Roland-Morris Disability Questionnaire (RDQ). Data were analyzed using parson's correlation and regression.

Results revealed that avoidant and ambivalent attachment styles negatively correlated with adjustment (positively correlated with depression, anxiety and stress) and positively with resiliency. Secure attachment wasn't correlated with none of them. Resiliency didn't mediate the impact of attachment style on adjustment. These findings suggest that insecure attachment style is a vulnerability factor for adjustment with chronic pain and predicts lower resiliency in these patients.

Briefly present the conclusions and importance of the results. Concisely summarize the study's implications. Please do not include any citations in the abstract.

Keywords:

attachment style, resiliency, adjustment, chronic pain.

Cite This Article: Sakineh Julaieha, Mahnaz Aliakbari Dehkordi, Farhad Shagaghi, Afsaneh Lak, and Marzieh kakanejadi fard, "RELATIONSHIP BETWEEN ATTACHMENT AND ADJUSTMENT WITH CHRONIC PAIN; WITH STUDY THE MODERATOR ROLE OF RESILIENCY” International Journal of Research - Granthaalayah, Vol. 4, No. 8 (2016): 52-61. 


\section{INTRODUCTION}

In recent years, attachment theory, which was originally formulated to describe and explain infant-parent emotional bonding, has been applied to the study of adolescent and adult romantic relationships and then to the study of psychological processes, such as interpersonal functioning, emotion regulation, coping with stress, and mental health[1] In particular, research on adult attachment processes and individual differences in attachment orientations has provided strong evidence for the anxiety-buffering function of what Bowlby [2] called the attachment behavioral system and for the relevance of attachment-related individual differences to coping with stress, managing distress, and retaining psychological resilience [3]. Resilience has been conceptualized as a dynamic developmental process encompassing the attainment of positive adaptation within the context of significant threat, severe adversity, or trauma. [4]. Resilience is a construct has flourished across many disciplines of psychology and health like positive psychology [5]. According to Zautra, Hall, and Murray [6], resilience is best defined as successful adaptation to adverse circumstances. Personal characteristics would determine resilience processes if those characteristics lead to healthy outcomes after the stressful situations [6]. Chronic pain is defined as recurrent or persistent pain lasting longer than the normal tissue healing time, approximately 3 to 6 months [7]. The Attachment-Diathesis Model of Chronic Pain [8] provides a framework for how insecure attachment may confer vulnerability for poor outcomes in chronic pain, particularly in the context of maladaptive cognitive appraisals such as perceptions of low selfefficacy. Given that pain is aversive and may present a threat to well-being, attachment processes could theoretically be activated by the experience of pain and influence individuals' response to pain. Consistent with this model, empirical studies have shown that insecure attachment is associated with chronic widespread pain [9]. Individuals with "insecure" adult attachment styles have been shown to experience more pain than people with secure attachment, though results of previous studies have been inconsistent. We performed a cross-sectional study on a large population-based sample to investigate whether, compared to pain free individuals, subjects with chronic widespread pain were more likely to report insecure adult attachment style [9] Results demonstrated that higher levels of secure attachment were associated with lower levels of activity avoidance, which was fully mediated by lower levels of pain catastrophizing; higher levels of preoccupied or fearful attachment were directly associated with higher levels over activity; higher levels of preoccupied attachment were associated with higher levels of activity avoidance, which was partially mediated by higher levels of pain catastrophizing; and higher levels of fearful attachment were indirectly associated with higher levels of activity avoidance through higher levels of catastrophizing[10]. Instead of focusing on deficits and vulnerabilities exclusively, this paper encourages that researchers and clinicians give more attention to how chronic pain patients may be resilient. One useful way of conceptualizing resilience to pain is to change one's perspective from looking for vulnerabilities to identifying one or more strengths that can foster resilient outcomes for people in pain. It is important to note that both stable personal characteristics (resilience resources) and more dynamic processes (resilience mechanisms) can play a prominent role in determining the effectiveness of individual pain adaptation. It is important to keep in mind the different ways that a person in pain may show resilience. The effect of resilience may be manifested in quicker recovery from the negative effects of pain, through the effective sustaining of positive functioning despite the presence of pain, and even through the realization of personal growth due to the presence of pain. It should be noted that individual differences are unquestionably present in the process of resilience to 
pain, both in recovery of homeostasis following upset and sustainability of positive engagements [11]. Terzi indicated that secure attachment style, and coping styles of active planning, avoidance/biochemical, and acceptance/cognitive restructuring were significant predictors of resilience. It was found that when secure attachment style scores were low, the presence of acceptance/cognitive restructuring orientation increased the resilience scores; while when the Secure attachment style scores were high, acceptance/cognitive restructuring did not influence the resilience scores [12]. According to above conversation we decided to investigate this question: Is resiliency has moderating role between attachment styles and coping with chronic pain?

\section{METHOD}

This study is causal-comparative and predictive variable is attachment and criterion variables, are depression, anxiety, stress, disability and resiliency. Examining relationships between variables, resilience also investigated the role of regulators Placed. The study population consisted of patients with chronic pain referred to Imam Khomeini hospital's multidisciplinary pain That 154 of them have been studied (according to the Cochran) purposive sampling. The mean age 47 (SD 16/59) years. A total of 41 per cent of men and 59\% of subjects were female (154). Subjects averages 40 months have been grappling with pain in different parts of the body, (SD: 68). The main site of pain in most patients (38\%) on the back and waist (36\%) were in the hands and feet and the pain in the other patients (26 percent) in neck, shoulders, chest and pelvis, respectively. The results showed that pain has disrupted the lives of the subjects: An average of 12 days because of the pain has been present in the workplace. (SD: 45). Compare the average hours of sleep before starting pain (6/21) and after the onset of pain (4/37) via t-test showed that pain significantly reduced sleep time(p: 0/01T:5/1) the subjects in this study to treat pain have resorted to various measures, for example, 74 percent of them have turned to drug use. (T: 1/5.)

\section{THE TOOLS USED IN THIS STUDY WERE}

Personal history and information about the Pain: This is a questionnaire with 16 questions, the patient interview is asked and contains information on the personal characteristics and other variables related to pain. Adult attachment AAI); [13]: Besharat using the test material attachment Hazan \& Shaver [14] set about Tehran University students standardization is a test of 15 questions and three levels of secure attachment, avoidant, and ambivalent in Q 5 Likert scale $(1=$ very little, $2=$ poor, $3=$ moderate, high and very high $=4=5)$ measures. The minimum and maximum score under the scales of the test subjects, respectively 5 and 25 . Cronbach's alpha coefficients of the scales queries secure, avoidant, and ambivalent about a sample of students) $1480(\mathrm{n}=$ including 860 girls and 620 boys for all the subjects vary from $850,84 / 0$ and vary from 850 to students 86/0, $83 / 0$ and 85/0 and for males 84/0, 85/0 and 86/0 was a sign of internal consistency good attachment scale adults. to assess validity of adult attachment Inventory the correlation coefficients between the scores of fifteen experts in psychology examined. Kendall's coefficients of agreement for secure attachment styles, avoidant, and ambivalent, respectively, 80/0, and 57/0 6.10 is calculated (enunciation 1384). Convergent validity through simultaneous performance measures of adult attachment problems Cooper Smith's self and self-esteem were assessed on a sample of 300 subjects and was approved [15]. 
Connor and Davidson Resilience Scale CS_RISC);[16]: The yardstick to measure the strength to cope with the pressure and threat. it Has 25 questions in Likert scale and is scoring between zero (completely false) to four (always true). The mean score of the scale is 52 and the participants score higher than 52 are more resiliencies and less resilience is even closer to zero. Examination of this scale in six general populations, referred to the primary care, outpatient psychiatry, patients with generalized anxiety disorder and post-traumatic stress. This scale was standardization by Mohammadi in Iran. The reliability of the Persian version with Cronbach's alpha was reported $89 \%$ [17].

Stress Anxiety Depression Scale-Short Form (DASS_21; [18]: The questionnaire with 21 items related to negative emotions (depression, anxiety and stress) is composed of three sub-scale that each subscale consists of 7 questions that subject should be raised after reading all the severity of symptoms using a 4-point scale from 0 to 3 rating scale from 0 to 21 and any change in Cronbach's alpha of this scale in a normative sample of 717 people has been reported for depression, anxiety and stress, 81 / 0,73 / 0 and 81/0 respectively [18]. In Iran, a Cronbach's alpha of 400 people in the general population is reported for depression, anxiety and stress 70 / 0 , $66 / 0$ and 76/0. [19]. And an issue in a study with 227 chronic pain patients reported is using confirmatory factor analysis and Cronbach's alpha of 3 functional verification tool for depression, anxiety and stress of 87 / 0,81 / 0 and 87 [20].DASS both long and short forms, each of which respectively 42 and 21 items. In this study, the short form is used.

Roland and Morris disability questionnaire and physical (RDQ; [21]: The questionnaire contains 24 questions with physical disabilities content causing the pain up. Patients' scores on these tests vary from zero to 24 and higher scores indicate more severe physical inability. Reliability and sensitivity of the questionnaire was confirmed among patients with chronic pain. Test-retest reliability of this scale through $91 / 0$ has been reported [21]. The psychometric properties of this test have been confirmed in Iranian patients with chronic pain. In the present study internal consistency (Cronbach's alpha) is $88 / 0$ [20].

\section{RESULTS AND DISCUSSIONS}

The results of correlation Table 1, shows the mean and standard deviation variables. The results showed that secure attachment relationship with resiliency variables and coping with chronic pain is not significant. In contrast, the pattern of correlations insecure styles are quite similar: avoidant attachment style with the resiliency) $\mathrm{r}=0 / 20$ :, $\mathrm{p}: 0 / 05$ ) significant negative correlation, and correlation with stress $(\mathrm{r}=0 / 219:, \mathrm{p}=01 / 0$, anxiety $(\mathrm{r}=0 / 176:, \mathrm{p}=0 / 05$ and depression $(\mathrm{r}=$ 0/376:, $\mathrm{p}=0 / 01)$ is a positive and significant. ambivalent, avoidant style with the resiliency $(\mathrm{r}=0 / 357:, \mathrm{p}=0 / 01)$ significant negative correlation, and correlation with stress $(\mathrm{r}=0$ / 444:, $\mathrm{p}=0 / 01)$, anxiety $(\mathrm{r}=0 / 313:, \mathrm{p}=0 / 01)$ and depression $(\mathrm{r}=0 / 444:, \mathrm{p}=0 / 01)$ is a positive and significant. According to cope with chronic pain variables in this study stress, anxiety, depression and physical disability is defined, a significant positive correlation with these variables ambivalent and avoidant style, meaning a significant negative relationship with consistency. 


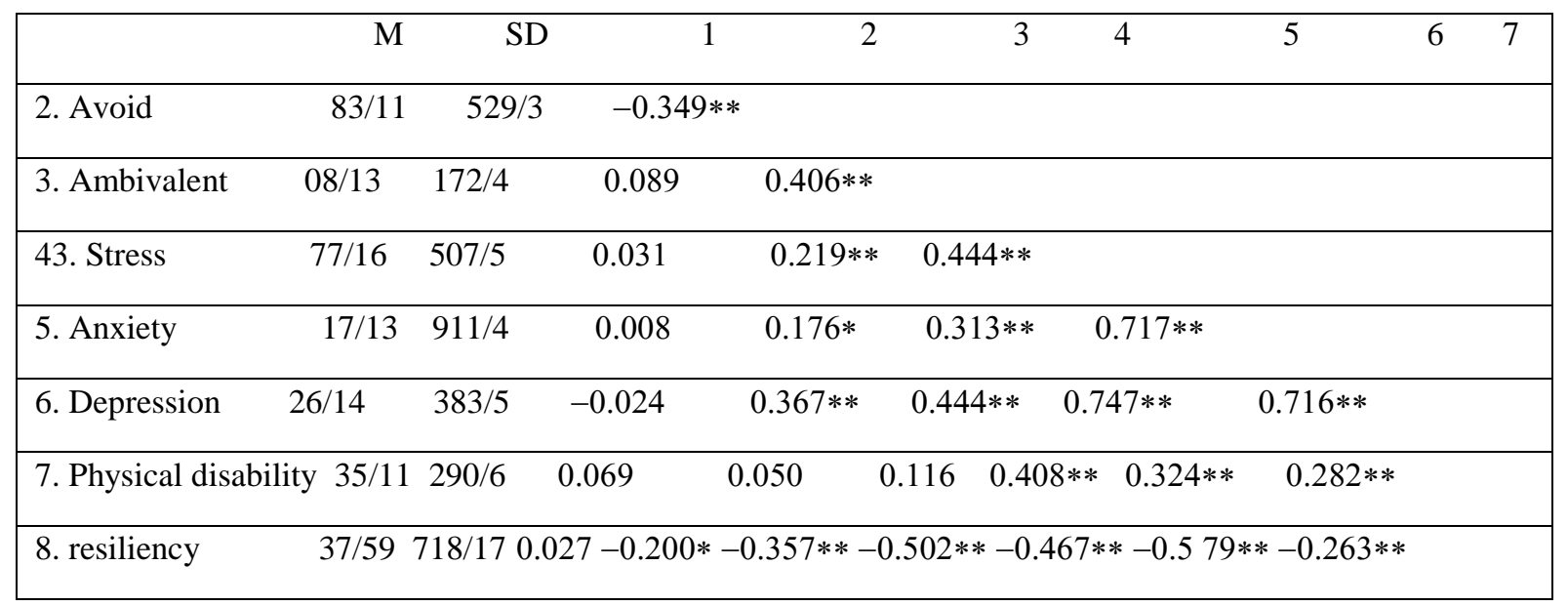

The Moderating Role of resiliency for attachment in connection with the depression, hierarchical regression was used. Just as impressive in Table 2, the first step attachment with dimensions of resilience, gender and age were entered as predictors. Coefficient of determination for this stage is significant. In the second step resilience sentences interaction with attachment styles were added to the equation. The improvement in the squared correlation was not significant at $0 / 002$. From this point of resiliency moderating relationship between attachment styles and depression hypothesis is rejected. Due to the addition of sentences interaction has not improved significantly in the equation, requires the presence of equations and equations with variables, attachment styles, resilience, gender and age as predictors of depression were reported in Table 2. In this equation, insecure attachment styles and resiliency with a negative coefficient with a positive coefficient are significant. That is less resiliency and avoid or ambivalent attachment scores higher, with higher levels of depression and this relationship is independent of gender, age and level of secure attachment score is achieved.

Table 2: examines the interaction of attachment styles and resiliency in predicting depression using hierarchical regression

\begin{tabular}{|c|c|c|c|c|}
\hline predictions & $\mathrm{R}$ & $\mathrm{R} 2$ change in $\mathrm{R} 2$ & F change degree of freedom 1 & degree of freedom2 significant \\
\hline & $0 / 662$ & $0 / 4390 / 439$ & $18 / 767$ & $\begin{array}{ll}144 & 0 / 000\end{array}$ \\
\hline
\end{tabular}

$\begin{array}{lllllll}0 / 664 & 0 / 441 & 0 / 002 & 0 / 193 & 3 & 141 & 0 / 901\end{array}$

Age + sex + attachment styles resiliency resiliency interaction and attachment

\begin{tabular}{lccccc}
\hline predictions & $\mathrm{B}$ & standard error & significant & $\beta$ & $\mathrm{t}$ \\
fixed amount & $13 / 145$ & $3 / 440$ & $-3 / 821$ & - & 0.000 \\
Resilience & $0 / 136$ & $-0 / 021$ & $0 / 449$ & $-6 / 414$ & $-0 / 000$ \\
Safe & $0 / 74$ & $0 / 109$ & $0 / 047$ & $0 / 676$ & $0 / 500$ \\
Avoidance & $0 / 338$ & $0 / 115$ & $0 / 221$ & $2 / 925$ & $0 / 004$ \\
Ambivalent & $0 / 257$ & $0 / 097$ & $0 / 200$ & $2 / 658$ & $0 / 009$ \\
Age & $0 / 005$ & $-0 / 23$ & $0 / 014$ & $-0 / 224$ & $-0 / 823$ \\
Sex & $0 / 623$ & $0 / 696$ & $0 / 057$ & $0 / 894$ & $0 / 373$
\end{tabular}

to investigate The Moderating Role of resiliency in relation to attachment with physical disabilities hierarchical regression was used. Just as impressive in Table 3, the first step 
attachment with dimensions of resilience, gender and age were entered as predictors. Coefficient of determination for this stage is significant. In the second step resilience sentences interaction with attachment styles were added to the equation. The improvement in the squared correlation was not significant at $0 / 023$. From Here hypothesis moderating relationship between attachment styles and resiliency of physical disability is rejected. In this equation, resiliency with a negative coefficient of age with a positive coefficient, are significant. That is fewer resiliencies and older, with higher levels of physical disability associated with this relationship is independent of sex and attachment scores.

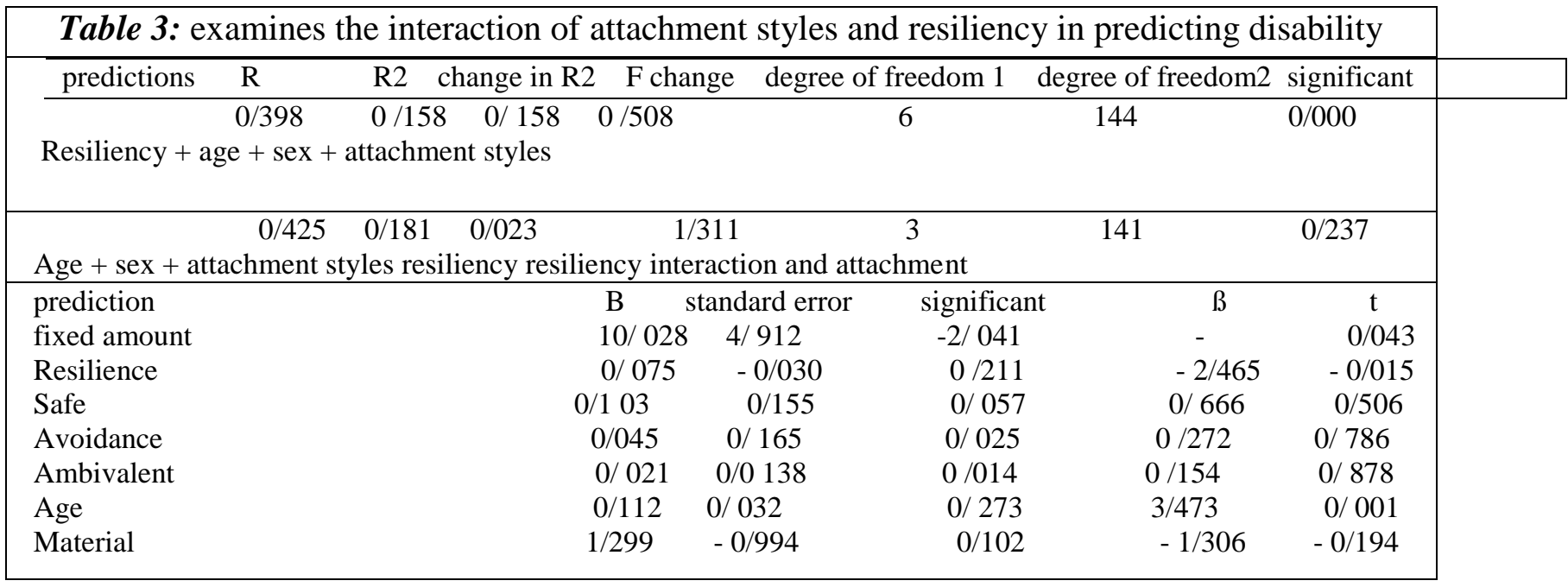

To investigate the role of resiliency moderator in the relationship between attachment style and anxious, hierarchical regression was used. Just as impressive in Table 4, the first step attachment with dimensions of resilience, gender and age were entered as predictors. Coefficient of determination for this stage is significant. In the second step resilience sentences interaction with attachment styles were added to the equation. The improvement in the squared correlation was not significant at $0 / 022$. From this point of moderating resiliency in relationship between attachment styles and anxiety hypothesis is rejected. Due to the addition of sentences interaction has not improved significantly in the equation, requires the presence of equations and equations with variables, attachment styles, resilience, gender and age as predictors of anxiety were reported in Table 4. In this equation, resilience to negative and ambivalent attachment style factor with a positive coefficient are significant. Resilience means less ambivalent attachment scores higher, with higher levels of anxiety and this relationship independent of age, sex and level score is secure and insecure attachment.

Table 4: Examines the interaction between attachment styles and resiliency in anticipation anxiety using hierarchical regression

\begin{tabular}{|c|c|c|c|c|c|c|c|}
\hline predictions & $\mathrm{R}$ & $\mathrm{R} 2 \mathrm{ch}$ & ange in R2 & F change & degree of freedom 1 & degree of freedom 2 & significant \\
\hline $\begin{array}{l}\text { Resiliency + age } \\
+ \text { sex + } \\
\text { attachment styles }\end{array}$ & $0 / 490$ & $0 / 240$ & $0 / 240$ & $7 / 586$ & 6 & 144 & $0 / 000$ \\
\hline $\begin{array}{l}++ \text { Age }+ \text { sex }+ \\
\text { attachment styles } \\
\text { and attachment }\end{array}$ & $\begin{array}{l}\text { resilienc } \\
0 / 512\end{array}$ & $0 / 262$ & $0 / 022$ & $1 / 419$ & 3 & 141 & $0 / 240$ \\
\hline
\end{tabular}




\begin{tabular}{|c|c|c|c|c|c|}
\hline predictions & B & standard error & significant & B & $\mathrm{t}$ \\
\hline fixed amount & $15 / 729$ & $3 / 636$ & $-4 / 325$ & - & 0.000 \\
\hline Resilience & $0 / 107$ & $-0 / 022$ & $0 / 368$ & $-4 / 744$ & $-0 / 000$ \\
\hline Safe & $0 / 019$ & $0 / 115$ & $0 / 014$ & $0 / 168$ & $0 / 867$ \\
\hline Avoidance & $0 / 053$ & $0 / 122$ & 0/ 039 & $0 / 438$ & $0 / 662$ \\
\hline Ambivalent & $0 / 191$ & 0/ 102 & $0 / 163$ & $0 / 87$ & $1 / 064$ \\
\hline Age & 0/007 & $0 / 024$ & $0 / 022$ & 0/ 294 & $0 / 769$ \\
\hline Sex & $0 / 048$ & $0 / 736$ & 0/ 005 & $0 / 066$ & $0 / 948$ \\
\hline
\end{tabular}

To assess The Moderating Role of resiliency in related attachment style to stress hierarchical regression was used. Just as impressive in Table 5, the first step attachment with dimensions of resilience, gender and age were entered as predictors. Coefficient of determination for this stage is significant. In the second step resilience sentences interaction with attachment styles were added to the equation. The improvement in the squared correlation was not significant at 0/007. From Here hypothesis moderating resiliency in relation with attachment styles and stress rejected. Due to the addition of sentences interaction has not improved significantly in the equation, requires the presence of equations and equations with variables, attachment styles, resilience, gender and age as predictors of stress were reported in Table 5. In this equation, resilience to negative factor, are significant. This means less resilience associated with higher levels of stress and this relationship is independent of gender, age and level of attachment scores.

Table 5: Examines the interaction between attachment styles and resiliency in anticipation of stress using hierarchical regression

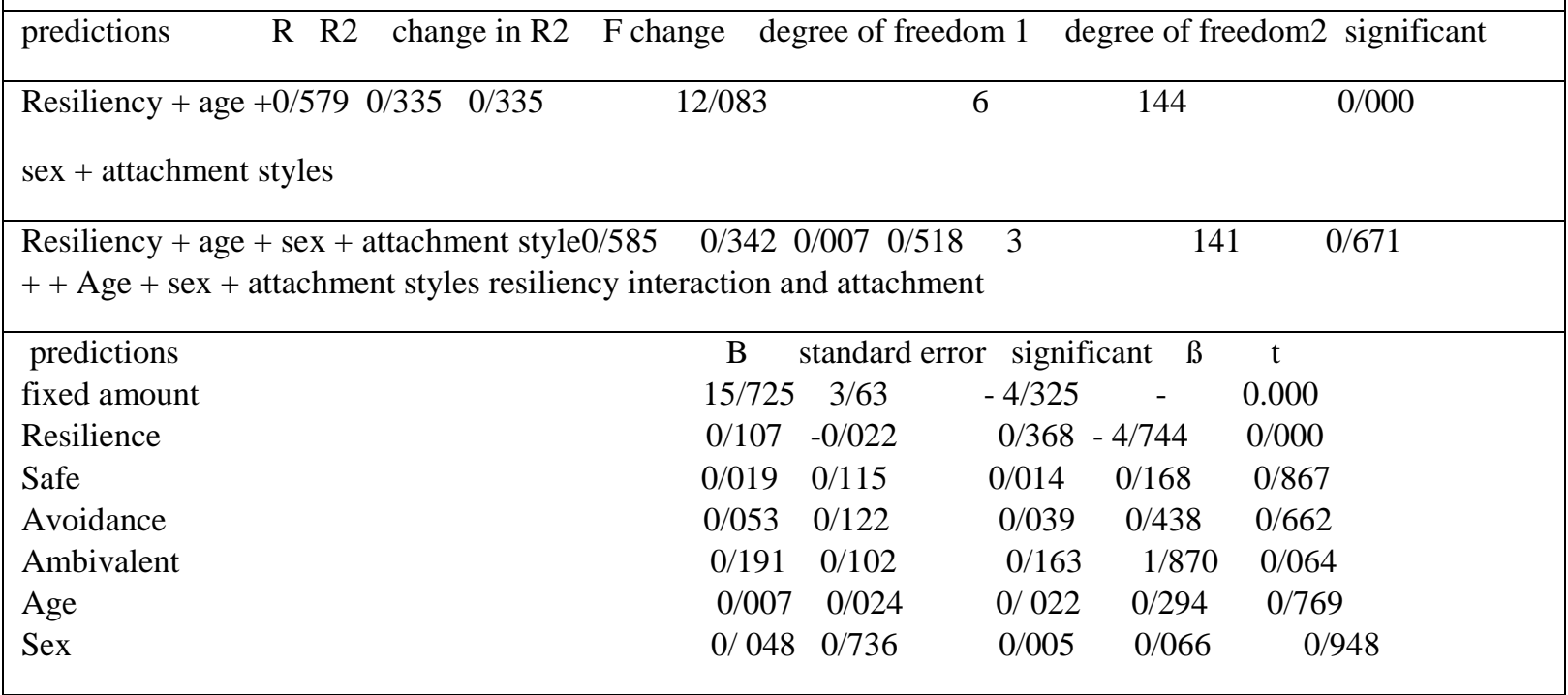

The findings suggest that there is a significant positive correlation, in patients with chronic pain between insecure attachment style with stress, anxiety and depression. Regression analysis indicates prediction about coping with pain insecure attachment style.

\section{DISCUSSION}

The findings suggest that there is a significant positive relationship; in patients with chronic pain between insecure attachment style with stress, anxiety and depression. Regression analysis also 
is about reflects a prediction insecure attachment style coping with chronic pain. can be said; The negative relationship with insecure attachment styles, coping with chronic pain and the role of insecure attachment style predict less compatibility with chronic pain. According to the interpersonal model of chronic pain [22] patients with chronic pain show mixed reactions based on attachment style to pain. These differences include differences in pain assessment, search and rallying support for health systems, self-disclosure, be able to Expressed concern, health cooperation and the focus is on the pain. Patients with avoidant attachment style insecure with excitement extreme control and try to needless to appear, the symptoms reported less than usual, despite little trouble to experts, And the interventions and prescribed medication which is resistant impairs treated[23]. These include therapies that use the therapeutic relationship to foster the development of a secure base such as meaning- and attachment-based intervention [24]. In these interventions, the development of a therapeutic secure base serves to facilitate new ways of thinking and feeling about the self, others and relationships [25]. In line with the commitment to this research study theoretical concept that "insecure attachment style risk / vulnerability in coping with chronic pain" [ 8]. These findings suggest that insecure attachment styles with physical disability was not significant and the analytical results is also indicative of the fact that insecure attachment styles (avoidant, ambivalent and) are not to be able to predict changes in disability scores. These findings are in line with the research [26-27-9]. In addition, regression analysis also showed that less resiliency and older, is associated with higher levels of physical disability. This study showed that between insecure attachment styles in chronic pain patients is associated with resilience. This is consistent with other studies that have found that individuals who are anxious about the availability and responsiveness of support (fearful or preoccupied attachment using the categories of Bartholomew and Horowitz) perceive their pain more negatively [28] and cope less well [29]. Ambivalent and avoidant attachment style have a significant negative correlation with the amount of resiliency. Attachment avoidance did not have a significant negative relationship to resilience. Bartholomew and Horowitz [30] report that individuals with levels of attachment avoidance have a defensively positive perception of themselves, which allows them to maintain independence from others. This may explain the current finding that attachment avoidance is unrelated to resilience. In addition, the study showed that between secure attachment style in chronic pain patients with chronic pain associated with resilience and adaptability there And secure attachment cannot predict the resiliency and coping with chronic pain. Studied showed that secure attachment style was associated with significantly lower levels of self-reported pain, pain behavior, disability and depressive symptoms in correlational analyses. Also, both insecure attachment styles characterized by negative models of the self (preoccupied and fearful) were associated with significantly higher levels of patientreported pain, pain behavior, disability, and depressive symptoms [31].

\section{CONCLUSIONS \& RECOMMENDATIONS}

Based on the findings, the answer to the question of whether the relationship between attachment styles and resiliency in coping with chronic pain is the role of moderator, were negative the results showed that the interaction resiliency with attachment styles significantly predicted has not changes consistent with chronic pain. Thus, according to the findings of this study seem a major role in insecure attachment style, even regardless of the person's resiliency, Still in place and that he is prone to incompatibilities in the face of adverse conditions such as chronic pain and generally can be concluded that attachment, As a dynamic and deep feature formed in the 
early years of childhood, its effects are lasting (and resiliency independent of the structure), the system of mental, behavioral, emotional and cognitive imposed by man.

\section{ACKNOWLEDGEMENTS}

Here is necessary to thankful and grateful to the management of doctor emami and his colleagues in imam Khomeini hospital.

\section{REFERENCES}

[1] MIKULINCER M, SHAVER PR. An attachment perspective on psychopathology. World Psychiatry. 2012; 11(1):11-15.)

[2] Bowlby J. Attachment and loss, Vol. 1. Attachment (2nd ed.) New York: Basic Books; 1982.

[3] Mikulincer M, Shaver PR. Attachment in adulthood: structure, dynamics, and change. New York: Guilford; 2007

[4] Resilience under conditions of extreme stress: a multilevel perspective. World Psychiatry. 2010; 9(3): 145-154.

[5] Yi-Frazier, J. P., Smith, R. E., Vitalino, P. P., Yi, J. C., Mai, S., Hillman, M., \& Weinger, $K$. (2009). A person-focused analysis of resilience resources and coping in patients with diabetes. Stress and Health, 10, 1-10.

[6] Zautra, A. J., Hall, J. S., \& Murray, K. E. (2010). Resilience: A new definition of health for people and communities. In: Reich, J, W., Zautra. A.J., \& Hall, J. S. Hnadbook of adult resilience. The Guilford Press, New York, London.

[7] American Pain Society Task Force on Pediatric Chronic Pain Management. Assessment and management of children with chronic pain. March 18, 2013, fromhttp://www.ampainsoc.org/advocacy/downloads/aps12-pcp.pdf

[8] Meredith P.Oensworth .T, Strong .J. A review of the evidence linking adult attachment theory and chronicpain: Presenting a conceptu model. Clinical Psychology Review 2008; 28. 407-429

[9] Davies KA, Macfarlane GJ, McBeth J, Morriss R, Dickens C. Insecure attachment style is associated with chronic widespread pain. Pain. 2009; 143(3):200-205. [PMC free article] [PubMed]

[10] Andrews NE, Meredith PJ, Strong J, Donohue GF. Adult attachment and approaches to activity engagement in chronic pain. Pain Research \& Management: The Journal of the Canadian Pain Society. 2014; 19(6):317-327.

[11] Sturgeon JA, Zautra AJ. Resilience: A New Paradigm for Adaptation to Chronic Pain. Current pain and headache reports. 2010; 14(2):105-112. doi:10.1007/s11916-0100095-9.

[12] Terzi, S. Secure attachment style, coping with stress and resilience among university students. The Journal of Happiness \& Well-Being, 2013, 1(2), 101-114

[13] Besharat, M. standardization of adult attachment scale. Research report, Tehran. University.1384

[14] Hazan, C., \& Shaver, P. R. Romantic love conceptualized as an attachment process. Journal of Personality and Social Psychology, 1987; 52,511-524. 
[15] Besharat, M., Shalchi, B. Attachment styles and coping. Journal of Developmental Psychology - Iranian psychologists 1386;3(11)

[16] Connor K. M., and Davidson J. R.T (2003) .Development a new resiliency scale: the Connor-Davidson Resiliency Scale (CS_RISC). DEPRESSION AND ANXIETY. 2003; 18: 76-82.

[17] Mohammadi, M.; Jazayeri, A., Rafiee, A.h .; Jowkar, B .; PurShahbaz, A. Factors resiliency in people at risk of drug abuse; Journal of psychologyTabriz University. $1385 ;$; first years 2 and 3, summer and fall

[18] Lovibond, PF., Lovibond, SH. The structure of negative emotional states: Comparison of the depression anxiety stress scales (DASS) with the beck depression and anxiety inventories. 1995; 33: 335-43.

[19] sahebi, AS., Asghari, m., salari, R. validation of Depression Anxiety and Stress Scale (DASS-21) for Iranian population. Journal of developmental psychology - Psychologists 1384; 1, (4), Summer 84.

[20] Asghari Moghaddam N.; Paknejad M.; Saedi, M.h.; Mehrabian F. Psychometric characteristics of depression, anxiety and stress in patients with chronic pain. Journal of Psychology 1389; 40 (1), Pages 42-13.

[21] Roland M., Morris R. A study of the natural history of back pain: Part I: Development of a reliable and sensitive measure of disability in low-back pain. 1983; 8; 141-144.

[22] Mikail, S. F., Henderson, P. R., \& Tasca, G. A. An interpersonally based model of chronic pain: An application of attachment theory. Clinical Psychology Review, 1994; 14, $1-16$.

[23] Hunter, J. J., \& Maunder, R. G. Using attachment theory to understand illness behavior. General Hospital Psychiatry, 2001; 23, 177-182.

[24] Bifulco A, Thomas G. Understanding Adult Attachment in Family Relationships. London: Routledge; 2013.

[25] Maunder R, Hunter J. An integrated approach to the formulation and psychotherapy of medically unexplained symptoms: Meaning-and attachment-based intervention. Am J Psychother. 2004; 58:17-33. [PubMed]

[26] Mc Williams, L.A. Cox, B. Impact of adult attachment style on pain and disability associated with arthritis in a nationally representative sample. Clinical Journal of Pain. 2000; 16, 361.

[27] Meredith P, Strong J, Feeney JA. Adult attachment, anxiety, and pain self-efficacy as predictors of pain intensity and disabiltiy. Pain. 2006; 123:146-154. [PubMed]

[28] Ciechanowski P., Sullivan M., Jensen M., Romano J., Summers H. The relationship of attachment style to depression, catastrophizing and health care utilization in patients with chronic pain. Pain. 2003; 104:627-637. [PubMed]

[29] Meredith P., Strong J., Feeney J.A. Adult attachment, anxiety, and pain self-efficacy as predictors of pain intensity and disability. Pain. 2006; 123:146-154. [PubMed]

[30] Bartholomew K., Horowitz LM. Attachment styles among young adults: A test of a fourcategory model. J Pers Soc Psychol. 1991; 61(2):226-244. [PubMed]

[31] Forsythe LP, Romano JM, Jensen MP, Thorn BE. Attachment Style Is Associated with Perceived Spouse Responses and Pain-Related Outcomes. Rehabilitation psychology. 2012;57(4):290-300. doi:10.1037/a0030083. 